\title{
Full picture discovery for mixed-fluorine anion effects on high-voltage spinel lithium nickel manganese oxide cathodes
}

\author{
Dae-wook Kim ${ }^{1,4}$, Hiromasa Shiiba ${ }^{1,4}$, Nobuyuki Zettsu ${ }^{1,2}$, Tetsuya Yamada ${ }^{2}$, Takeshi Kimijima ${ }^{2}$, \\ Gabriel Sánchez-Santolino ${ }^{3}$, Ryo Ishikawa ${ }^{3}$, Yuichi Ikuhara ${ }^{3}$ and Katsuya Teshima ${ }^{1,2}$
}

Small amounts of fluorine substituting for oxygen deficiencies could reduce Mn dissolution, enhancing the cyclability in spinel-type lithium nickel manganese oxides $\left(\mathrm{LiNi}_{0.5} \mathrm{Mn}_{1.5} \mathrm{O}_{4}\right)$. Fluorine anion incorporation simultaneously enhances the $\mathrm{C}$-rate capability and specific capacity fading. We used experimental and theoretical approaches to obtain a full picture of the mixedanion effects for $\mathrm{LiNi}_{0.5} \mathrm{Mn}_{1.5} \mathrm{O}_{4-{ }_{x}} \mathrm{~F}_{x}$ cathode materials. The fluorine anion reduced the activation barrier for lithium-ion hopping along the most energetically preferable $8 a-16 c-8 a$ route, enhancing the C-rate capability. Simultaneously, the coordination bond of the linear $\mathrm{F}^{-}-\mathrm{Mn}^{3+}-\mathrm{F}^{-}$(Mn@2F diagonal) arrangement increased the oxidation potential to $5.1 \mathrm{~V}$ (vs $\mathrm{Li}^{+} / \mathrm{Li}^{2}$. This hampered full extraction of $\mathrm{Li}^{+}$from the spinel lattice, which was triggered by the oxidation of $\mathrm{Mn}^{3+}$ below the cutoff voltage (3.5-4.8 $\mathrm{V}$ (vs $\left.\mathrm{Li}^{+} / \mathrm{Li}\right)$ ), leading to a capacity loss.

NPG Asia Materials (2017) 9, e398; doi:10.1038/am.2017.90; published online 7 July 2017

\section{INTRODUCTION}

Lithium (Li)-ion secondary batteries have improved our lifestyles over the past two decades. ${ }^{1}$ However, the technical requirements for $\mathrm{Li}$-ion secondary batteries are entering a phase of major change with respect to the energy density, which will require higher-energy-density cathode materials. ${ }^{2}$ The cathode's energy density depends on the specific capacity, tap density, loading amount and average operating voltage of the active materials. High-voltage materials could reduce the number of serially connected cells and enhance the energy density.

Spinel-type $\mathrm{LiNi}_{0.5} \mathrm{Mn}_{1.5} \mathrm{O}_{4}$ (LNMO) is a 5 - $\mathrm{V}$ level high-voltage active material because of the high redox potential of $\mathrm{Ni}^{2+} / \mathrm{Ni}^{4+}$ (vs $\left.\mathrm{Li}^{+} / \mathrm{Li}\right){ }^{3-6}$ LNMO can be crystallographically classified into two spinel structures: ordered $\mathrm{P}_{3} 32$ space group and disordered $\mathrm{Fd}-3 \mathrm{~m}$ space group (cubic symmetry). Formation of an oxygen vacancy at the $24 e$ site is critical for determining the symmetry and accompanying the reduction of $\mathrm{Mn}^{4+}$ to $\mathrm{Mn}^{3+}$ because of the charge balance. Recently, we performed density function theory (DFT) calculations to evaluate the formation energy using oxygen vacancy and metal-excess models for ordered and disordered $\mathrm{LiNi}_{0.5} \mathrm{Mn}_{1.5} \mathrm{O}_{4-\delta}\left(\mathrm{LNMO}_{4-\delta}\right) .^{7}$ Oxygen vacancy formation reactions were unlikely, although interstitial cation occupation occurred at the octahedral vacancies in both $\mathrm{P}_{3} 32$ and Fd-3m $\mathrm{LNMO}_{4-\delta}$ spinel compounds.

The formation of $\mathrm{Mn}^{3+}$ in the LNMO lattice typically decreases the operating voltage, making the energy density lesser than that of stoichiometric LNMO. ${ }^{8-12}$ An excess of $\mathrm{Mn}^{3+}$ could produce structural distortions and disproportionations, degrading the cycle capability during high-voltage operations. ${ }^{13-15}$ Alternatively, the ordered $\mathrm{P}_{3} 32$ phase has a limited power density. Low electron conductivity (two orders of magnitude lower than that of the $F d-3 m$ LNMO) caused capacity fading in the high C-rate charge-discharge reaction. ${ }^{12,16,17}$

We showed that tuning the $\mathrm{Mn}^{3+}$ concentration is important for suitable electrochemical characteristics. Substitution of the transition metal cation with $\mathrm{Ni}^{2+}$ and/or $\mathrm{Mn}^{4+}$ is a plausible way to tune the valence state of the manganese ion, which distributes defects in the spinel structure. Partial substitution of a cation ( $\mathrm{Cr}, \mathrm{Fe}, \mathrm{Mg}, \mathrm{Zn}$ or $\mathrm{Ru}$ ) into the $\mathrm{Ni}$ and $\mathrm{Mn}$ sites provides a better performance than that of the pure structure. ${ }^{18-26}$

Mixed-anion compounds (e.g., oxyfluoride) could enhance the electrochemical performance. A small amount of fluorine substitution for oxygen could reduce $\mathrm{Mn}$ dissolution (from hydrogen fluoride attack) and enhance the cyclability. ${ }^{27,28}$ The incorporation of fluorine anions $\left(\mathrm{F}^{-}\right)$simultaneously enhanced the C-rate capability and capacity fading. ${ }^{29,30}$ However, the origin of the enhanced electrochemical performance is not fully understood in relation to the electrical and structural properties, ${ }^{31-34}$ which are affected by the electronic and ionic conductivities. Because of the higher electronegativity, the $\mathrm{F}^{-}$could interact with the $\mathrm{Li}^{+}$, causing an increased activation barrier for $\mathrm{Li}^{+}$hopping along the $8 a-16 c-8 a$ path in the spinel framework.

\footnotetext{
${ }^{1}$ Department of Materials Chemistry, Faculty of Engineering, Shinshu University, Nagano, Japan; ${ }^{2}$ Center for Energy and Environmental Science, Shinshu University, Nagano, Japan and ${ }^{3}$ Institute of Engineering Innovation, The University of Tokyo, Tokyo, Japan

${ }^{4}$ These authors contributed equally to this work.

Correspondence: Professor N Zettsu or Professor K Teshima, Center for Energy and Environmental Science, Shinshu University, 4-17-1 Wakasato, 380-8553, Nagano, Japan. E-mail: zettsu@shinshu-u.ac.jp or teshima@shinshu-u.ac.jp

Received 19 December 2016; revised 23 February 2017; accepted 24 March 2017
} 
Here, we address this contradictory issue for $\mathrm{LiNi}_{0.5} \mathrm{Mn}_{1.5} \mathrm{O}_{4-x} \mathrm{~F}_{x}$ (LNMOF) cathode materials using experimental and theoretical approaches. Many fundamental studies have been carried out on cation-substitution effects, but there are only a few reports on mixed-anion effects. Therefore, determining the full picture for mixed-anion effects of high-voltage spinel systems provides new methods for material design that overcome the current performance limitations.

\section{MATERIALS AND METHODS}

\section{Flux growth and characterization of LNMOF crystals} $\mathrm{LNMO}_{4-\delta}$ crystals were grown by LiCl-KCl flux growth. ${ }^{35}$ We performed a two-step flux growth for the LNMOF crystals with different amounts of fluorine substitution, including the flux growth of $\mathrm{LNMO}_{4-\delta}$ crystals from the $\mathrm{LiCl}-\mathrm{KCl}$ flux and subsequent fluorine anion incorporation in a molten $\mathrm{KCl}$ flux. For the incorporation of the fluorine anion, the $\mathrm{LNMO}_{4-\delta}$ crystal was reacted with $\mathrm{LiF}$ in a $\mathrm{KCl}$ flux $\left(800{ }^{\circ} \mathrm{C}, 20 \mathrm{~h}\right)$ at different $\mathrm{LiF}$ concentrations. The powders were washed with warm water to remove the remaining $\mathrm{KCl}$ flux and annealed under an $\mathrm{O}_{2}$ atmosphere $\left(700^{\circ} \mathrm{C}, 10 \mathrm{~h}\right)$. The phases and structures of the crystals were identified using X-ray diffraction (XRD) analysis with a $\mathrm{Cu}-\mathrm{K} \alpha$ radiation source. The X-ray diffractometer (Miniflex II; Rigaku, Tokyo, Japan) was operated at $30 \mathrm{kV}$ and $20 \mathrm{~mA}$, with $2 \theta=10-80^{\circ}$ (scan step $=0.02$ ). Field emission scanning electron microscopy (JSM-7600F at $15 \mathrm{kV}$; JEOL, Tokyo, Japan) observations were conducted to examine the microstructural characteristics in the crystals. The valence state of the $\mathrm{Mn}$ ion and atomic percent of incorporated fluorine atoms were studied by X-ray photoelectron spectroscopy (XPS) with a monochromic Al-Ko source (JPS$-9010 \mathrm{MX}$ at $15 \mathrm{kV}, 15 \mathrm{~mA}$; JEOL). All binding energies in the spectra were referenced to the $\mathrm{C} 1 \mathrm{~s}$ hydrocarbon peak at $284.5 \mathrm{eV}$. The etching thickness was controlled at $20 \mathrm{~nm}$ per Ar sputtering, which was calculated in relation to the silicon wafer. The orders of the $\mathrm{Ni}$ and $\mathrm{Mn}$ configurations were characterized by Raman spectroscopy with $532 \mathrm{~nm}$ excitation (LabRAM, Horiba, Japan). The electrochemical characteristics were evaluated using a coin-type cell (R2032-type). The cathode was prepared by a conventional pasting process and contained LNMOF crystals, acetylene black and polyvinylidene fluoride (90:5:5 wt \%). The mixture was diluted with $N$-methyl-2-pyrrolidone to give a viscosity of $\sim 5.1 \mathrm{~Pa}$.s. The prepared paste was homogeneously coated onto a $20-\mu \mathrm{m}$-thick $\mathrm{Al}$ foil using a slit coater. The electrode density was adjusted to $3.0 \mathrm{~g} \mathrm{~cm}^{-3}$ using a press machine. All electrodes were dried at $120^{\circ} \mathrm{C}$ in a vacuum oven before cell assembly. Li metal foil and a porous polypropylene film (\#2500; Celgard, Charlotte, NC, USA) were used as the counter electrode and separator, respectively. A solution of $1 \mathrm{M} \mathrm{LiPF}_{6}$ in a mixture of ethylene carbonate and dimethyl carbonate (1:1 vol.\%) was used as the electrolyte. The coin-type cells were assembled in an Ar-filled glovebox (MDB-2BL; Miwa Mfg, Osaka, Japan) with a controlled atmosphere containing < $<$ p.p.m. $\mathrm{H}_{2} \mathrm{O}$ and $\mathrm{O}_{2}$. The galvanostatic charge-discharge tests and electrochemical impedance spectroscopy (EIS) were performed using a potentio/galvanostat (HJ1020Msd8 (Hokuto Denko, Tokyo, Japan); VSP-300 (Bio-Logic, Seyssinet-Pariset, France)). The cutoff voltage range for the battery tests was controlled between 3.5 and $4.8 \mathrm{~V}$ vs $\mathrm{Li} / \mathrm{Li}^{+}$. The frequency range for the EIS measurements was $1 \mathrm{MHz}-0.001 \mathrm{~Hz}$. All EIS measurements were performed at $23^{\circ} \mathrm{C}$ in a constant-temperature chamber (SU-221; Espec, Hudsonville, MI, USA).

\section{X-ray absorption fine-structure spectroscopy}

Ex situ Mn K edge X-ray absorption fine-structure spectroscopy (XAFS) spectra were measured to evaluate the changes in the electrochemical states of the LNMOF crystal-based cathodes with different states of charge (SOCs) using the BL15A1 beamline of the Photon Factory (High Energy Accelerator Research Organization (KEK) in Tsukuba, Japan). The XAFS spectra were recorded from 6300 to $6900 \mathrm{eV}$ in transmission mode. Each sample was measured for $\sim 90 \mathrm{~min}$. The spectral energy was calibrated using that of $\mathrm{Mn}_{2} \mathrm{O}_{3}$. LNMOF electrodes were removed from a disassembled coin cell after three cycles and used as samples for the XAFS measurements. The SOCs were controlled at 0 and $75 \%$, respectively, before disassembly. The capacities of these SOCs were carefully estimated from their first-cycle discharge capacities. We disassembled the cells and washed them with dimethyl carbonate in an Ar-filled glove box. The samples were kept in a dried Ar atmosphere until the XAFS measurements.

\section{DFT simulation}

The DFT calculations were performed using the generalized gradient approximation (GGA-PBEsol) $+\mathrm{U}$ and projector-augmented wave methods as implemented in the Vienna $a b$ initio simulation package. ${ }^{36-39}$ The $U$-values for the $d$-orbitals of $\mathrm{Ni}$ and $\mathrm{Mn}$ were set to 6.0 and $3.9 \mathrm{eV}$, respectively. ${ }^{40-42}$ The magnetic ground state of LNMO exhibits ferrimagnetic ordering ( $\mathrm{Ni} \downarrow \mathrm{Mn} \uparrow$ ), as reported in previous experimental and computational studies. ${ }^{31,43-45}$ Thus, the ferrimagnetic spin configurations were used for all the calculations in this study. An energy cutoff of $500 \mathrm{eV}$ and a $3 \times 3 \times 3 k$-point mesh were used for the superstructure of 56 atoms in a cubic spinel lattice of $8\left(\mathrm{LiNi}_{0.5} \mathrm{Mn}_{1.5} \mathrm{O}_{4}\right)$ with $P_{3} 32$ symmetry as a starting structure. To realize the atomic arrangement of 8 $\left(\mathrm{LiNi}_{0.5} \mathrm{Mn}_{1.5} \mathrm{O}_{4-}{ }_{x} \mathrm{~F}_{x}\right)(0.125 \leq x \leq 0.375)$, we added $1-3$ fluorine anions into the possible $24 e$ and $8 c \mathrm{O}$ oxygen sites in the unit cell of $\mathrm{LiNi}_{0.5} \mathrm{Mn}_{1.5} \mathrm{O}_{4-x} \mathrm{~F}_{x}$ $(0.125 \leq x \leq 0.375)$. The nudged elastic band method was used to investigate the minimum energy pathways of Li hopping from one lattice position to adjacent sites. ${ }^{46,47}$ Relaxation of the crystal structure was allowed for all calculations, and the final energies of the optimized geometries were recalculated to correct for changes of the plane-wave basis during relaxation.

\section{Surface energy of the bulk model and surface model}

We manually arranged the atoms on the LNMOF surface while retaining their crystallographic symmetry and chemical stoichiometry for calculating $E_{\text {slab }}$ (the energy of a slab with a surface facet). The crystallographic symmetry of the top and bottom slab surfaces is essential for achieving a rational computational prediction. Therefore, the same analogy for calculating $E_{\text {slab }}$ cannot be applied to the structures for $x=0.125$ and 0.375 because of their asymmetric $\mathrm{O} / \mathrm{F}$ arrangement. In this work, we evaluated the surface energies for only $\mathrm{LNMO}_{3.75} \mathrm{~F}_{0.25}(x=0.25)$.

The surface energies, $\gamma$, are defined as

$$
\gamma=\frac{1}{2 A}\left(E_{\text {slab }}-N E_{\text {bulk }}-\sum_{i=O, F} \Gamma_{i} \mu(i)\right),
$$

where $A$ is the surface area of slab, $E_{\text {bulk }}$ is the energy per atom of the bulk model and $N$ is the number of atoms in the slab model. The third term indicates the chemical potentials of excess or deficient oxygen and fluorine atoms for non-stoichiometric slab models. In this work, the chemical potentials of oxygen and fluorine were fixed as oxygen gas and fluorine gas, respectively, based on DFT calculations. The slab cells were constructed from the relaxed bulk structure, and the lattice parameters were fixed for the slab cells. For the calculations of the surface facets, slab thicknesses $>20 \AA$ were chosen for all facets with vacuum thicknesses of $20 \AA$.

\section{Scanning transmission electron microscopy}

Direct observation of an original atomic surface structure requires clean and electron transparent thin scanning transmission electron microscopy (STEM) specimens. We simply put the LNMOF powders in ethanol and dispersed them onto a perforated amorphous carbon grid, rather than using the conventional Ar-ion thinning method to avoid significant surface damages. The atomic-resolution annular bright-field $(\mathrm{ABF})$ and annular dark-field ( $\mathrm{ADF}$ ) STEM images were acquired using an aberration-corrected JEM ARM300CF instrument (JEOL) installed at the University of Tokyo, equipped with a cold-field emission gun and electron energy-loss spectroscopy (EELS, Quantum; Gatan, Pleasanton, CA, USA). To suppress the beam damage to Li-containing materials, we operated our microscope at $80 \mathrm{kV}$ at a relatively low-dose condition $(\sim 13 \mathrm{pA})$, and no significant structure changes were observed during image acquisition. The used convergence semiangle was $27 \mathrm{mrad}$ and the collection angles were 13-27 and 70-200 mrad for ABF- and ADF-STEM imaging, respectively.

\section{RESULTS AND DISCUSSION}

Figures $1 \mathrm{a}-\mathrm{c}$ shows the most stable $\mathrm{O} / \mathrm{F}$ arrangements for (a) $x=0.125$, (b) $x=0.25$ and (c) $x=0.375$ in LNMOF. We 
a

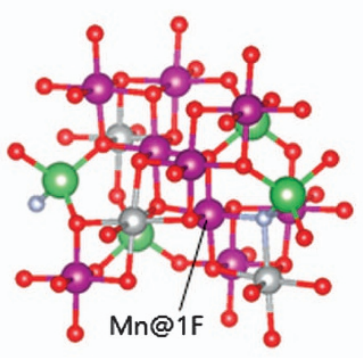

b

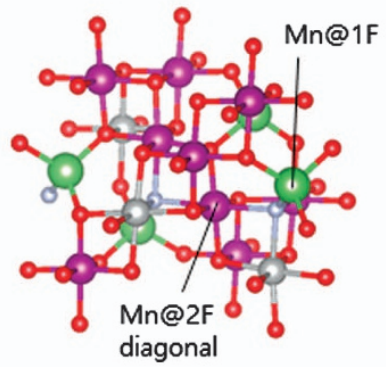

C Mn@2F orthogonal

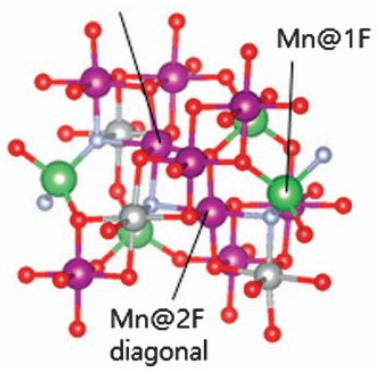

d
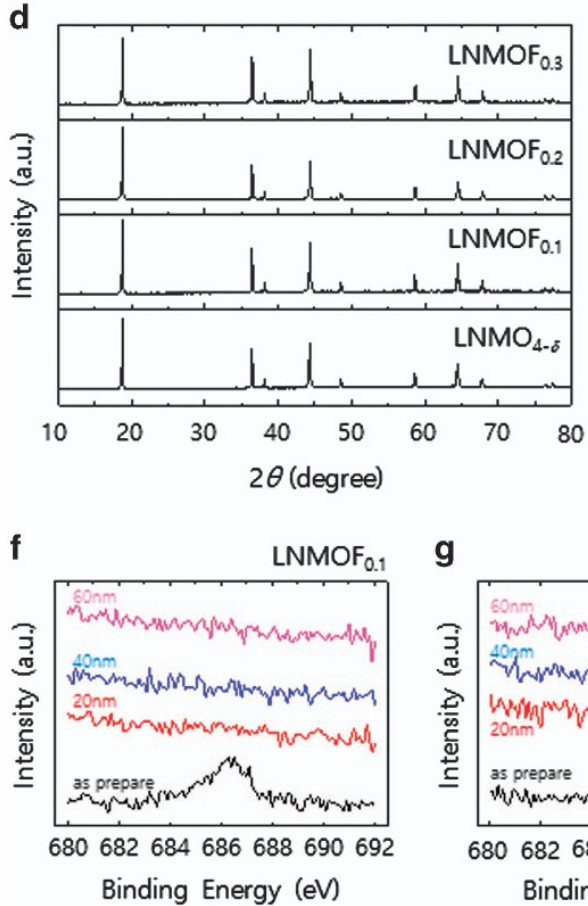

e

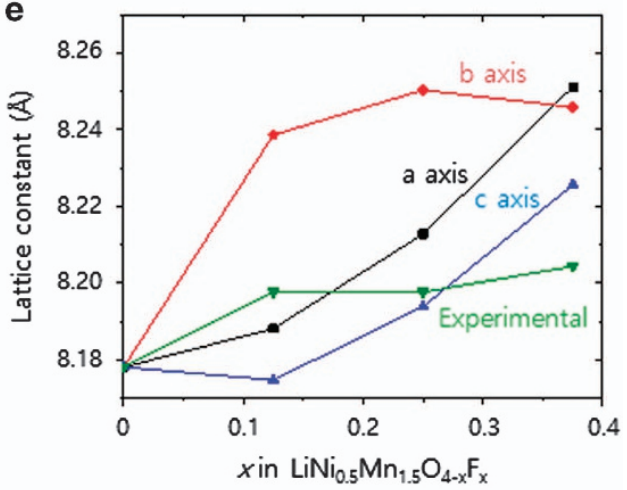

g

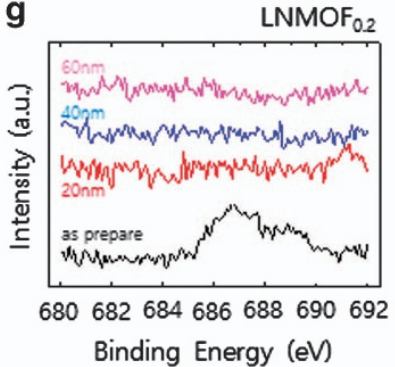

$\mathrm{h}$

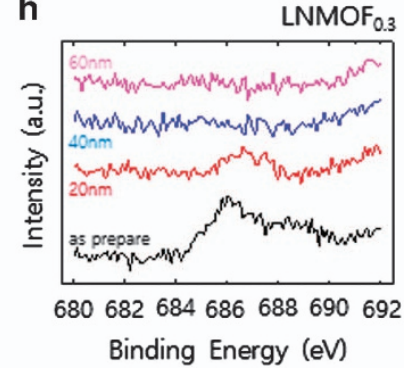

Figure 1 Experimental and computational studies on the fluorine anion distribution inside the spinel frame work and the $\mathrm{crystals}$ of $\mathrm{LiNi}_{0.5} \mathrm{Mn}_{1.5} \mathrm{O}_{4-{ }_{x}} \mathrm{~F}_{x}$ (LNMOF). All possible O/F arrangements were considered to determine the most stable 2, 13 and 9 different $\mathrm{O} / \mathrm{F}$ arrangements, which were calculated for $x=0.125,0.25$ and 0.375 , respectively: (a) $x=0.125$, (b) $x=0.25$ and (c) $x=0.375$ in $\mathrm{LiNi}_{0.5} \mathrm{Mn}_{1.5} \mathrm{O}_{4-x} \mathrm{~F}_{x}$. (d) $\mathrm{X}$-ray diffraction (XRD) patterns of LNMOF crystals with various amounts of fluorine anion incorporation. XRD patterns taken from all of the prepared samples are in good agreement with the reference data of ICDD PDF 70-8650 ( $\left.\mathrm{LiNi}_{0}{ }_{5} \mathrm{Mn}_{1.5} \mathrm{O}_{4}\right)$ with a small shift from fluorine addition. (e) The lattice parameters of LNMOF determined from the XRD patterns and density function theory (DFT) calculations. Series of F1s X-ray photoelectron core-level spectra: (f) LNMOF 0.1 , (g) LNMOF 0.2 and (h) LNMOF 0.3 with varying Ar spattering etching thicknesses (black: as prepared; red: $20 \mathrm{~nm}$; blue: $40 \mathrm{~nm}$; and pink: $60 \mathrm{~nm}$ ).

considered all possible $\mathrm{O} / \mathrm{F}$ arrangements to determine the most stable arrangements; 2, 13 and 9 different $\mathrm{O} / \mathrm{F}$ arrangements were calculated for $x=0.125,0.25$ and 0.375 , respectively. The energy differences between the most stable and second most stable arrangements for $x=0.125,0.25$ and 0.375 were $0.48,0.29$ and $0.07 \mathrm{eV}$, respectively. $\mathrm{F}^{-}$preferentially occupied the $24 e \mathrm{O}$ sites instead of the $8 \mathrm{c}$ sites, independent of the amount of $\mathrm{F}^{-}$substitution. The same tendency was noted for oxygen vacancy formation in the non-stoichiometric $\mathrm{LNMO}_{4-\delta}$ system (e.g., the formation energy for 24e O site occupation in $\mathrm{LiNi}_{0.5} \mathrm{Mn}_{1.5} \mathrm{O}_{3.875} \mathrm{~F}_{0.125}\left(\mathrm{LNMOF}_{0.1}\right)$ was $\sim 0.48 \mathrm{eV}$ lower than that for $8 c \mathrm{O}$ site occupation). $\mathrm{F}^{-}$coordinated with two $\mathrm{Mn}^{3+}$ ions and one $\mathrm{Ni}^{2+}$ ion. Furthermore, $\mathrm{Mn}^{4+}$ in the $\mathrm{LNMO}_{4-\delta}$ lattice was reduced to $\mathrm{Mn}^{3+}$ as the same number of $\mathrm{F}^{-}$ions was introduced into the structure. The incorporated $\mathrm{F}^{-}$reduced the neighboring $\mathrm{Mn}^{4+}$ to $\mathrm{Mn}^{3+}$. A linear $\mathrm{F}^{-}-\mathrm{Mn}^{3+}-\mathrm{F}^{-}$cluster formed in $\mathrm{LiNi}_{0.5} \mathrm{Mn}_{1.5} \mathrm{O}_{3.75} \mathrm{~F}_{0.25}$ $\left(\mathrm{LNMOF}_{0.2}\right)$ along the $b$-axis in octahedral $\mathrm{MnO}_{6}$ (24e sites occupied by $\mathrm{F}^{-}$(Mn@2F diagonal)). Further, incorporated $\mathrm{F}^{-}$occupied other nearest-neighboring $24 e$ site. Two different configurations were formed in the $\mathrm{LiNi}_{0.5} \mathrm{Mn}_{1.5} \mathrm{O}_{3.625} \mathrm{~F}_{0.375} \quad\left(\mathrm{LNMOF}_{0.3}\right)$ lattice (linear and bent for $\mathrm{F}^{-}-\mathrm{Mn}^{3+}-\mathrm{F}^{-}$( $\mathrm{Mn} @ 2 \mathrm{~F}$ neighbor) clusters in octahedral $\mathrm{MnO}_{6}$ ). The bond length of $\mathrm{Mn}^{3+}-\mathrm{F}^{-}$in the Mn@2F diagonal arrangement was longer than that of the Mn@2F neighboring arrangement, indicating that Jahn-Teller distortion possibly elongated the direction of the Mn@2F diagonal arrangement (parallel to the $b$-axis).

The powder XRD patterns for all flux-growth samples were in good agreement with the reference data (ICDD PDF 70-8650; Figure 1d). All $\mathrm{F}^{-}$-substituted LNMOF crystals were of single phase. Chemical composition analysis based on inductively coupled plasma optical emission spectrometry revealed that all the LNMOF crystals had almost stoichiometric compositions (Supplementary Table S1). The difference in the $\mathrm{F}$ contents for data obtained from the experiments and that used in the calculations are negligible from a crystallographic point of view. We used a superstructure composed of 56 atoms $\left(\mathrm{F}_{0.125}\right.$ 

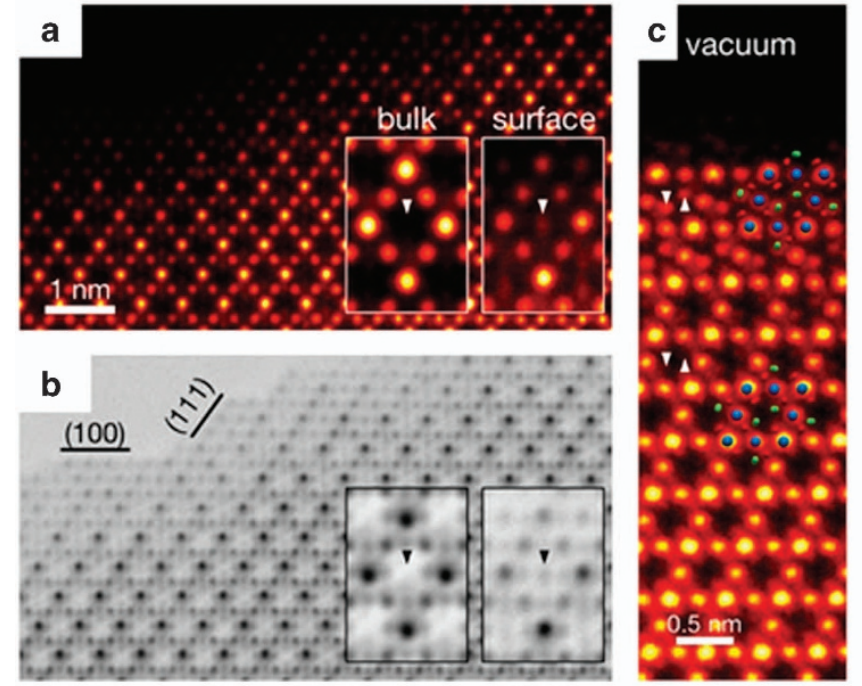
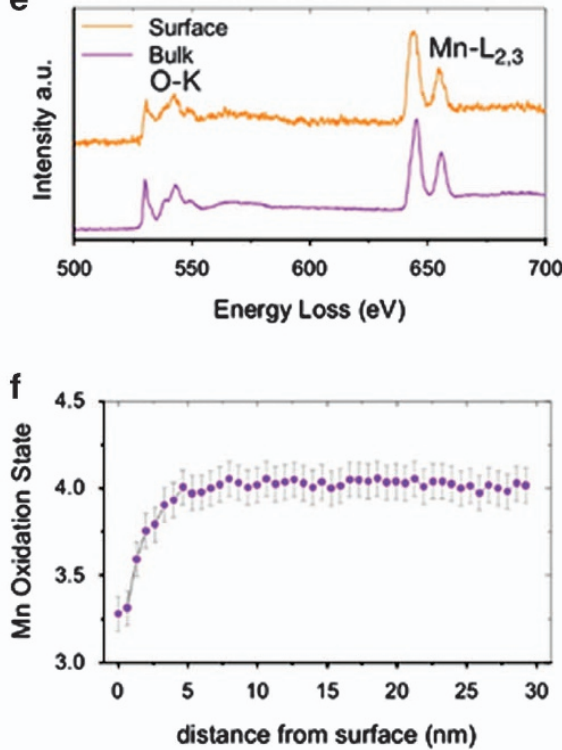

Figure 2 Characterization of the surface atomic and electronic structures of $\mathrm{LiNi}_{0.5} \mathrm{Mn}_{1.5} \mathrm{O}_{4-x} \mathrm{~F}_{x}$ (LNMOF) by scanning transmission electron microscopy (STEM). ( $\mathbf{a}$ and $\mathbf{b}$ ) annular dark-field (ADF)- and annular bright-field-STEM (ABF-STEM) images obtained for LNMOF, (c and d) ADF- and ABF-STEM images obtained from the $\left(\begin{array}{lll}1 & 1 & 1\end{array}\right)$ surface, (e) electron energy-loss spectroscopy (EELS) profiles (O-K and Mn- $\left.L_{2,3}\right)$ obtained from the top surface and a few nanometers inside this region. (f) $\mathrm{Mn}$ oxidation state as a function of distance from the surface using the EELS Mn- $\mathrm{L}_{2,3}$ edges.

(Li: 8, Ni: 4, Mn: 12, O: 31, F: 1), $\mathrm{F}_{0.25}$ (Li: 8, Ni: 4, Mn: 12, O: 30, F: 2), and $\mathrm{F}_{0.375}$ (Li: 8, Ni: 4, Mn: 12, O: 29, F: 3)) for our computation. The chemical formula can be described as $\mathrm{LiNi}_{0.5} \mathrm{Mn}_{1.5} \mathrm{O}_{3.875} \mathrm{~F}_{0.125}$, where one fluorine anion is substituted with $\mathrm{O}$ in the unit cell. We believe that such a negligible difference will not exert any significant effects on these findings.

Figure 1e represents the lattice parameters determined from the XRD patterns and DFT calculations. There was little difference for the $\mathrm{LNMO}_{4-\delta}$ crystals with no $\mathrm{F}^{-}$substitution, which shows the theoretical validity of our model. The XRD experiments indicated lattice parameter changes that occurred with increasing $\mathrm{F}^{-}$substitution. The relatively small increase of the lattice parameter in highly fluorinated LNMOF may be from passivation of the oxygen deficiency by the $\mathrm{F}^{-}$at the defect site. Our calculations predicted a crystal structure transition from a cubic to orthorhombic system with $\mathrm{F}^{-}$substitution, accompanied by an anisotropic lattice dilatation along the $b$-axis (caused by Jahn-Teller distortion).

We examined the XPS F1s spectral depth profile to elucidate the incompatibility between the experimental and computation results for the lattice parameters (Figures 1f-h). The changes of the F1s core-level spectra as a function of Ar sputtering time represent the intensity of the XPS F1s core-level spectrum, which became extremely weak after the $20 \mathrm{~nm}$ etching, and no XPS F1s signals were detected after $40 \mathrm{~nm}$ of etching. The remarkable changes in the depth profile indicated that $\mathrm{F}^{-}$ions were disproportionally incorporated at the crystal surface (which is strongly supported by the DFT calculation). Supplementary Figure S1 represents the energetically most stable atomic arrangements for the surface level at the (a) (1 00 ), (b) (1 110$)$ and (c) (1 111$)$ plane and for the core level at the (d) (1 000$),\left(\right.$ e) $\left(\begin{array}{lll}1 & 1 & 0\end{array}\right)$ and (f) (1 111$)$ plane in $\mathrm{LiNi}_{0.5} \mathrm{Mn}_{1.5} \mathrm{O}_{4-x} \mathrm{~F}_{x}\left(x=0.27\right.$ for $\left(\begin{array}{lll}1 & 0 & 0\end{array}\right), x=0.25$ for $\left(\begin{array}{lll}1 & 1 & 0\end{array}\right)$ and (1 111 )). Supplementary Table $\mathrm{S} 2$ shows the calculated surface energies from these models; the surface energy of the bulk model was higher than that of the surface model, independent of the crystal faces. $\mathrm{F}^{-}$preferentially passivated the oxygen vacancy formed at the surface to stabilize the crystal surface. Moreover, the antisite energy for $\mathrm{Ni} / \mathrm{Mn}$ ordering decreased with respect to $\mathrm{F}^{-}$substitution (Supplementary Table S3). The highest $\mathrm{F}^{-}$substitution $(x=0.375)$ made the antisite energy negative, indicating that $\mathrm{Ni} / \mathrm{Mn}$ disordering preferentially occurred and promoted the phase transition from an ordered to disordered structure.

Mixed $\mathrm{F}^{-}$influenced the morphology of the LNMOF crystals. The field emission scanning electron microscopy observation clearly visualized the formation of a step-terrace structure at the flat $\left\{\begin{array}{lll}1 & 1 & 1\end{array}\right\}$ plane and truncation at the vertices and edges of the parental octahedral structure (Supplementary Figure S1). The truncated lattice faces were assigned to the $\left\{\begin{array}{lll}1 & 0 & 0\end{array}\right\}$ faces, bearing a higher surface energy than the $\left\{\begin{array}{lll}1 & 1 & 1\end{array}\right\}$ face. Thus, the incorporated $\mathrm{F}^{-}$potentially reduced the surface energy of the $\left\{\begin{array}{lll}1 & 0 & 0\end{array}\right\}$ faces compared with the standard LNMO phase. This is most evident in the atomic-resolution ADF and ABF-STEM images observed in the $\left[\begin{array}{lll}1 & 1 & 0\end{array}\right]$ crystallographic orientation of $\mathrm{LNMOF}_{0.2}$ (Figures $2 \mathrm{a}$ and $\mathrm{b}$ ). The surface is not flat but has two components of the $\left\{\begin{array}{lll}1 & 0 & 0\end{array}\right\}$ and $\left\{\begin{array}{lll}1 & 1 & 1\end{array}\right\}$ surface steps, which is consistent with the field emission scanning electron microscopy observations in Supplementary Figure S2. A close inspection of the topmost surface indicates that a rock-salt like (similar to nickel oxide) atomic structure was formed at a thickness of a few unit cells, as evident from the cell-averaged inset images in Figures $2 \mathrm{a}$ and $\mathrm{b}$ : a new atomic site appears on the diamond center, as marked by arrowheads. However, in the $\left\{\begin{array}{lll}1 & 1 & 1\end{array}\right\}$ topmost surface, there appears antisite defect spinel structures that seem to form at a thickness of a few unit cells; transition metals might be occupied at $\mathrm{Li}$ atomic sites, as marked by arrowheads in Figures $2 \mathrm{c}$ and $\mathrm{d}$. Based on the formation of the rock-salt and antisite spinel structure, we conclude that the amount of $\mathrm{Li}$ ions is lacking within a few unit cells from the surface because of their elution into water during flux removal.

Figure 2e shows EELS spectra of $\mathrm{O}-\mathrm{K}$ and $\mathrm{Mn}-\mathrm{L}_{2,3}$ edges obtained from the topmost surface and bulk regions $(10 \mathrm{~nm}$ inside of the surface), respectively. Clearly, the intensity of the $\mathrm{O}-\mathrm{K}$ pre-edge was substantially reduced at the top surface. The Mn oxidation state as a function of distance from the surface, where we 
a

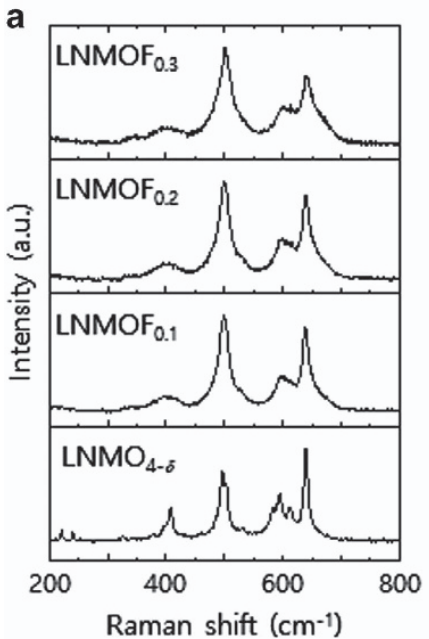

b

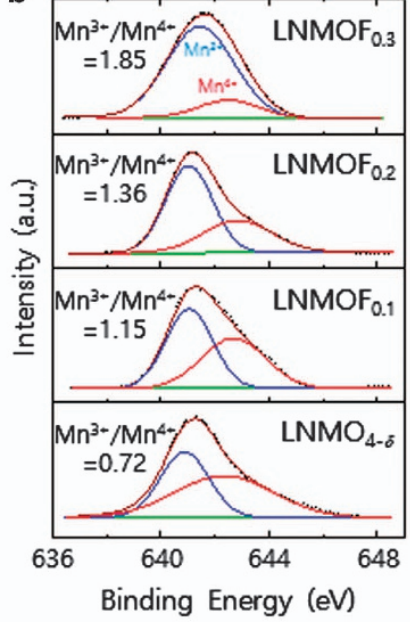

C

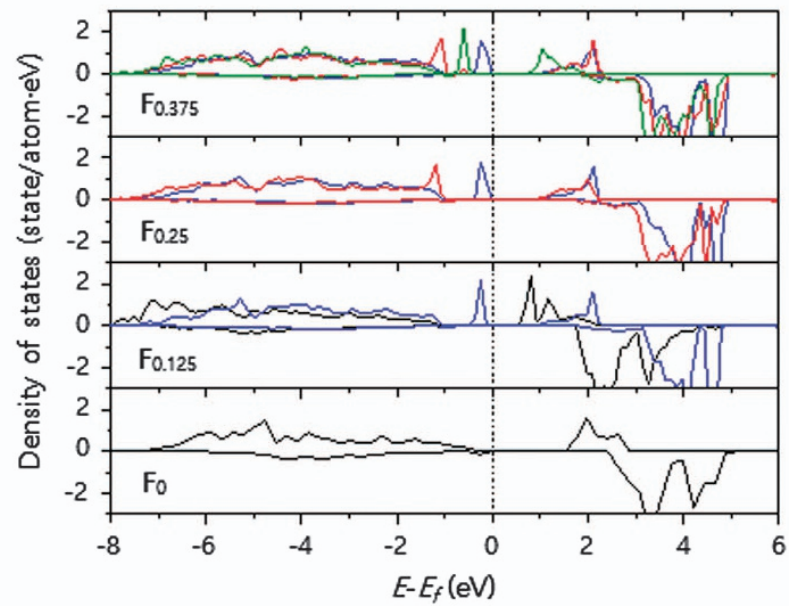

Figure 3 Impact of fluorine anion incorporation on the Ni/Mn arrangements. (a) Raman spectra and (b) X-ray photoelectron spectroscopy (XPS) Mn 2p spectra of LNMOF crystals. The broad peak can be deconvoluted into two peaks, which were assigned to $\mathrm{Mn}^{3+}$ (blue) and $\mathrm{Mn}^{4+}$ (red) species. (c) Partial densities of state (PDOSs) for the Mn-3d band in $\mathrm{LiNi}_{0.5} \mathrm{Mn}_{1.5} \mathrm{O}_{4-x} \mathrm{~F}_{x}(0 \leq x \leq 0.375)$ (black: Mn@0F; blue: Mn@1F; red: Mn@2F diagonal; and dark green: Mn@2F neighbor).
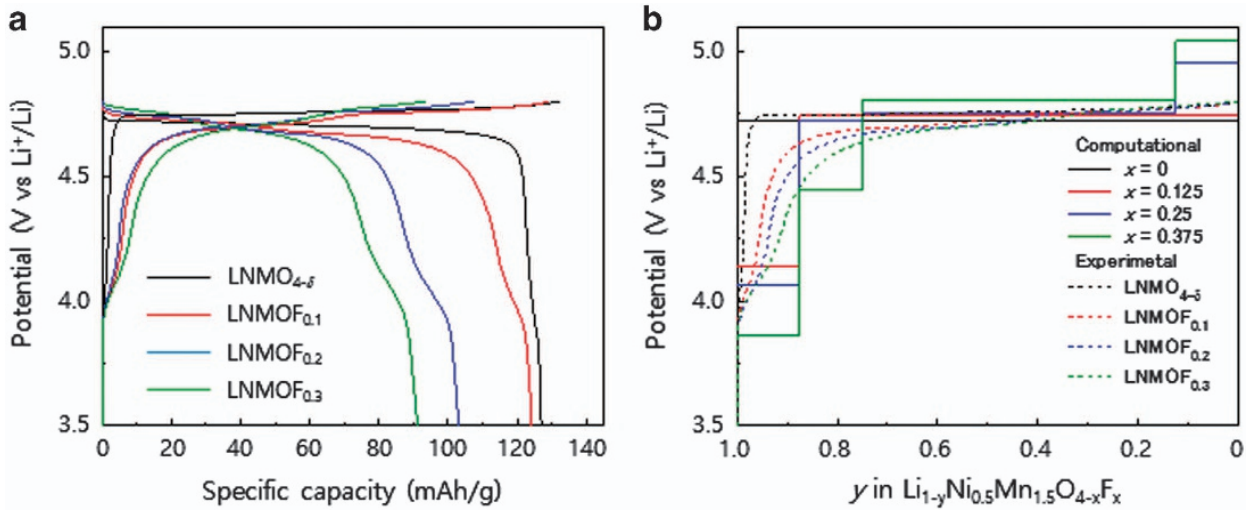

Figure 4 Galvanostatic charge-discharge profiles of $\mathrm{LiNi}_{0.5} \mathrm{Mn}_{1.5} \mathrm{O}_{4-x} \mathrm{~F}_{x}$ (LNMOF) crystal cathodes/Li cells. (a) Galvanostatic charge-discharge curves in the cutoff voltage range of 3.5-4.8 $\left(0.2\right.$ C-rate and $\left.23^{\circ} \mathrm{C}\right)$ and $(\mathbf{b})$ computationally predicted and experimentally obtained voltage profiles during the charging reaction as a function of Li content in the LNMOF systems.

used EELS Mn- $\mathrm{L}_{2,3}$ edges, revealed that the Mn oxidation is close to $\mathrm{Mn}^{3+}$ and gradually decreased the amount of $\mathrm{Mn}^{3+}$ within the top few nanometers of the surface (Figure 2f). Based on both the O-K prepeak reduction and the increase of the $\mathrm{Mn}^{3+}$ contents at the surface, we conclude that a certain amount of oxygen vacancies should remain within the top few nanometers of the surface region, despite the incorporation of $\mathrm{F}^{-}$.

The effect of $\mathrm{F}^{-}$on the ordering of the Ni/Mn arrangement in the $\mathrm{LNMO}_{4-\delta}$ lattice was studied using Raman spectroscopy. Intense Raman signals at 498 and $638 \mathrm{~cm}^{-1}$ (assigned to ordered $\mathrm{Ni}-\mathrm{O}$ and Mn-O stretching bands, respectively) in the spinel lattice were diminished by the incorporation of $\mathrm{F}^{-}$independent of the substitution (Figure 3a). The mixed $\mathrm{F}^{-}$may have highly randomized the $\mathrm{Ni} / \mathrm{Mn}$ arrangement. The proportion of $\mathrm{Mn}^{3+} / \mathrm{Mn}^{4+}$ examined by XPS (Figure 3b) also strongly supports our consideration. Two peaks attributed to $\mathrm{Mn}^{3+}$ and $\mathrm{Mn}^{4+}$ were observed in the $\mathrm{Mn} 2 \mathrm{p}$ core-level spectra. The $\mathrm{Mn}^{3+} / \mathrm{Mn}^{4+}$ ratio was 0.72 for the $\mathrm{LNMO}_{4-\delta}$ crystals and increased with $\mathrm{F}^{-}$substitution, which agrees with our computational predictions (1.15 for $\mathrm{LNMOF}_{0.1}, 1.36$ for $\mathrm{LNMOF}_{0.2}$ and 1.85 for $\mathrm{LNMOF}_{0.3}$ ). Our DFT calculation also predicted that $\mathrm{Mn}^{4+}$ was reduced to $\mathrm{Mn}^{3+}$ in the $\mathrm{LNMO}_{4-\delta}$ lattice when the same number of $\mathrm{F}^{-}$was introduced.

Figure $3 \mathrm{c}$ shows the calculated partial densities of state (PDOSs) for the manganese ions in $\mathrm{LiNi}_{0.5} \mathrm{Mn}_{1.5} \mathrm{O}_{4-x} \mathrm{~F}_{x}(0 \leq x \leq 0.375)$. At $x=0.125$, one $\mathrm{Mn}-3 \mathrm{~d}$ band appeared near the Fermi level, indicating that the electron was doped in Mn-3d through the formation of a Mn@1F bond, giving $\mathrm{Mn}^{3+}$. Mn@2F and $\mathrm{Mn} @ 1 \mathrm{~F}$ formed at $x=0.25$. The $\mathrm{Mn}-3 \mathrm{~d}$ bands appeared near the Fermi level. The Mn-3d bands originating from Mn@2F shifted from -0.2 to $-1.2 \mathrm{eV}$, compared with that at $x=0.125$. Thus, the $\mathrm{Mn}^{3+}$ ions were stabilized and became inactive redox couples against the applied voltage of $4.0 \mathrm{~V}\left(\mathrm{vs} \mathrm{Li}^{+} / \mathrm{Li}\right)$. This stabilization effect is likely associated with the enhanced Jahn-Teller distortion of $\mathrm{Mn}^{3+}$ by the two linearly arranged $\mathrm{F}^{-}$ions coordinated with $\mathrm{Mn}^{3+}$ along the direction parallel to the distortion. At $x=0.375$, additional Mn-3d bands for Mn@2F appeared at $-0.6 \mathrm{eV}$. Moreover, the antisite energy for $\mathrm{Ni} / \mathrm{Mn}$ ordering decreased with respect to $\mathrm{F}^{-}$substitution (Supplementary Table S3). Finally, the highest $\mathrm{F}^{-}$substitution $(x=0.375)$ made the antisite energy negative, indicating that $\mathrm{Ni} / \mathrm{Mn}$ disordering preferentially occurred and promoted the phase transition from an ordered to disordered structure. 
a

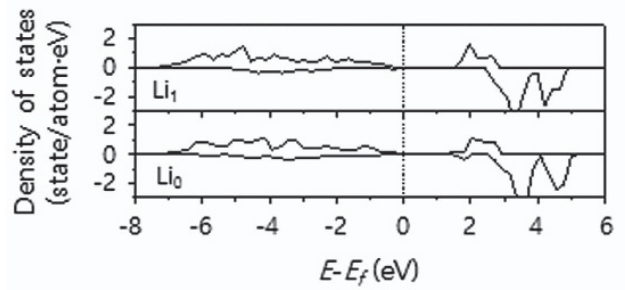

c

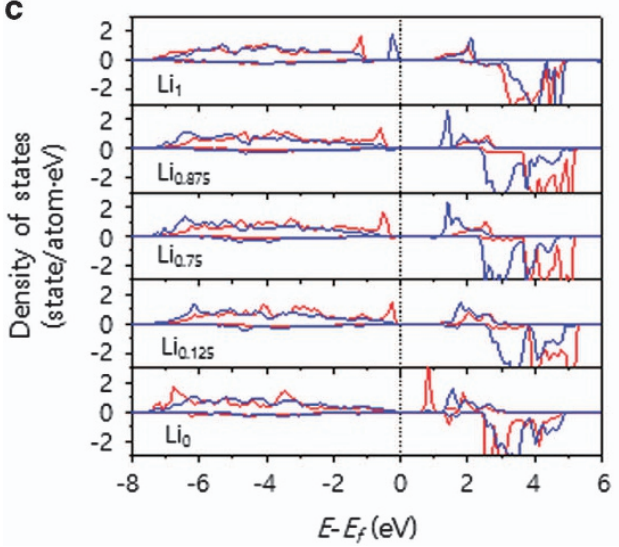

b

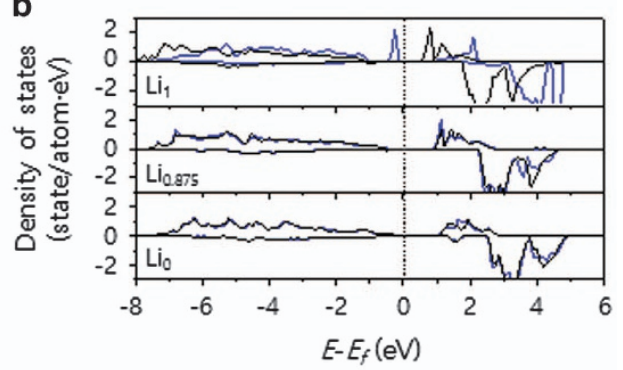

d

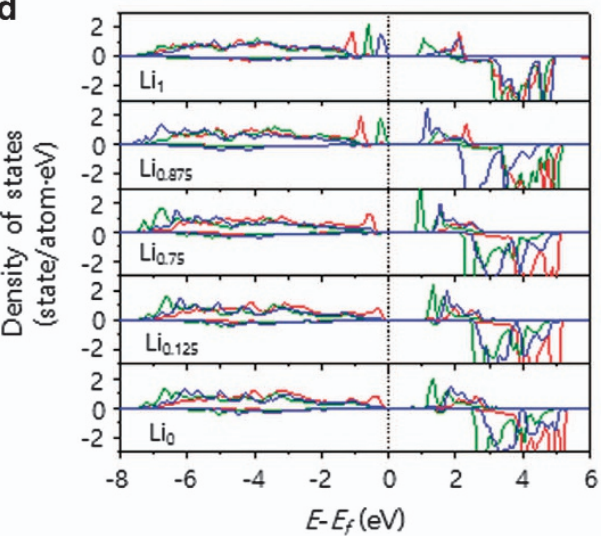

Figure 5 Changes in the partial densities of state (PDOSs) for $\mathrm{Mn}-3 \mathrm{~d}$ bands at different lithium compositions. (a) LiNi ${ }_{0.5} \mathrm{Mn}_{1.5} \mathrm{O}_{4}$, (b) $\mathrm{LiNi}_{0.5} \mathrm{Mn}_{1.5} \mathrm{O}_{3.875} \mathrm{~F}_{0.125}\left(\mathrm{LNMO}_{0.1}\right)$ (c) $\mathrm{LiNi}_{0.5} \mathrm{Mn}_{1.5} \mathrm{O}_{3.75} \mathrm{~F}_{0.25}\left(\mathrm{LNMO}_{0.2}\right)$ and (d) $\mathrm{LiNi}_{0.5} \mathrm{Mn}_{1.5} \mathrm{O}_{3.625} \mathrm{~F}_{0.375}\left(\mathrm{LNMO}_{0.3}\right)$ (black: $\mathrm{Mn} @ 0 \mathrm{~F}$; blue: $\mathrm{Mn} @ 1 \mathrm{~F} ;$ red: $\mathrm{Mn@2F} \mathrm{diagonal;} \mathrm{and} \mathrm{dark} \mathrm{green:} \mathrm{Mn@2F} \mathrm{neighbor).}$

Galvanostatic charge-discharge tests at various C-rates were systematically performed to examine the effect of $\mathrm{F}^{-}$substitution on the battery performance, including the rate capability. Figure $4 \mathrm{a}$ shows the third charge-discharge cycle profiles at $30 \mathrm{~mA} \mathrm{~g}^{-1}$, corresponding to a $0.2 \mathrm{C}$-rate showed that the $\mathrm{F}^{-}$substitution affected the voltage slope characteristics. Discontinuous sharp changes of the flat voltage were observed in the LNMOF crystals during the charge-discharge reactions from 4.6 to $4.9 \mathrm{~V}$ in the discharge reaction, indicating that two redox couples $\left(\mathrm{Ni}^{2+} / \mathrm{Ni}^{3+}\right.$ and $\left.\mathrm{Ni}^{3+} / \mathrm{Ni}^{4+}\right)$ separately appeared. An inflexion point in the voltage slope at $\sim 4.0 \mathrm{~V}$ was detected, which was assigned to the redox response from $\mathrm{Mn}^{3+} / \mathrm{Mn}^{4+}$. Supplementary Figure S3 shows the cyclic voltammetry of the $\mathrm{LNMO}_{4-\delta}$ and LNMOF crystals. From 4.6 to $4.9 \mathrm{~V}$, two peaks were separated, corresponding to the $\mathrm{Ni}^{2+} / \mathrm{Ni}^{3+}$ and $\mathrm{Ni}^{3+} / \mathrm{Ni}^{4+}$ redox pairs, which were the origin of the voltage step at the lower $\mathrm{Li}$-content region in the voltage profiles (Figure 4a). ${ }^{31,48}$ The $\mathrm{Mn}^{3+} / \mathrm{Mn}^{4+}$ redox peak increased as the mixed $\mathrm{F}^{-}$increased (caused by charge valence). Meanwhile, the fluorine anion narrowed the potential gap compared with that of $\mathrm{LNMO}_{4-\delta}$ (shown in the redox potential gap for $\mathrm{Ni}^{2+} / \mathrm{Ni}^{3+}$ ). The reduction of the redox potential gap implies a faster lithiation-delithiation reaction in the disordered $\mathrm{Ni} / \mathrm{Mn}$ configuration by incorporating $\mathrm{F}^{-} .49$

As shown in Figure 4a, the capacities faded with respect to $\mathrm{F}^{-}$substitution. The $\mathrm{LNMOF}_{0.3}$ cathode/Li cell had the lowest discharge capacity, which was three-quarters of the discharge capacity in the $\mathrm{LNMO}_{4-\delta}$ cathode/Li cell. The DFT calculations provided a full picture of this intriguing phenomenon. The changes in the most stable atomic structure as a function of the Li composition were computed using the formation energies of LNMOF with different atomic arrangements (Supplementary Figure S4). The plausible reaction routes during the charge-discharge reaction and the voltage slopes were computationally predicted (Figure 4b). Our computational studies duplicated the voltage profile characteristics of the charging process from 3.5 to $5.0 \mathrm{~V}$. The LNMO electrode showed a flat voltage as delithiation at $\sim 4.7 \mathrm{~V}$, assigned to oxidation of $\mathrm{Ni}^{2+}$ to $\mathrm{Ni}^{4+}$, whereas the LNMOF electrodes displayed two distinct plateaus at $\sim 4.7 \mathrm{~V}$ and an additional small plateau at $\sim 4.0 \mathrm{~V}$ attributed to the oxidation of $\mathrm{Mn}^{3+}$ to $\mathrm{Mn}^{4+}$. There was no intermediate phase once the oxidation state of all manganese ions reached the tetravalent state. Thus, the two-phase region coexisted during the oxidation of $\mathrm{Ni}^{2+}$ to $\mathrm{Ni}^{4+}$ in the charge process. ${ }^{31,50,51}$ The computational and experimental results indicated that the delithiation energy of LNMO was almost constant for $0 \leq \mathrm{Li} \leq 1$. In contrast, the formation of an oxygen deficiency in the LNMO lattice changed the manganese oxidation state from $\mathrm{Mn}^{4+}$ to $\mathrm{Mn}^{3+}$; a small portion of the manganese remained as $\mathrm{Mn}^{3+}$ in the LNMO/Li cell. In fact, crystal growth in a molten salt tends to occur with the lack of oxygen partial pressure, leading to an oxygen defect spinel compared with the solid-state reaction in an oxygen atmosphere.

Our calculations provide new information about the mixed- $\mathrm{F}^{-}$ effects on the electrochemical reaction, including capacity fading. Several voltage steps were observed in both the higher and lower Li-content regions, including a phase transformation triggered by the $\mathrm{Mn}^{3+} / \mathrm{Mn}^{4+}, \mathrm{Ni}^{2+} / \mathrm{Ni}^{3+}$ and $\mathrm{Ni}^{3+} / \mathrm{Ni}^{4+}$ oxidation reactions. Higher delithiation energies than that of fully-lithiated LNMO $(\mathrm{Li}=1)$ are required in the lower $\mathrm{Li}$-content region $(\mathrm{Li} \leq 0.125)$ because of the increased $\mathrm{Li}$ vacancy formation energy. The $\mathrm{Li}$ ions stored in the LNMOF lattice were not completely electrochemically extracted, causing capacity fade.

The computationally predicted PDOS of LNMOF with different Li compositions showed that the $\mathrm{Mn}^{3+}$ ions were oxidized preferentially to $\mathrm{Mn}^{4+}$ during the delithiation reaction. For instance, manganese ions show little changes in PDOS when the Li composition is reduced, and, 

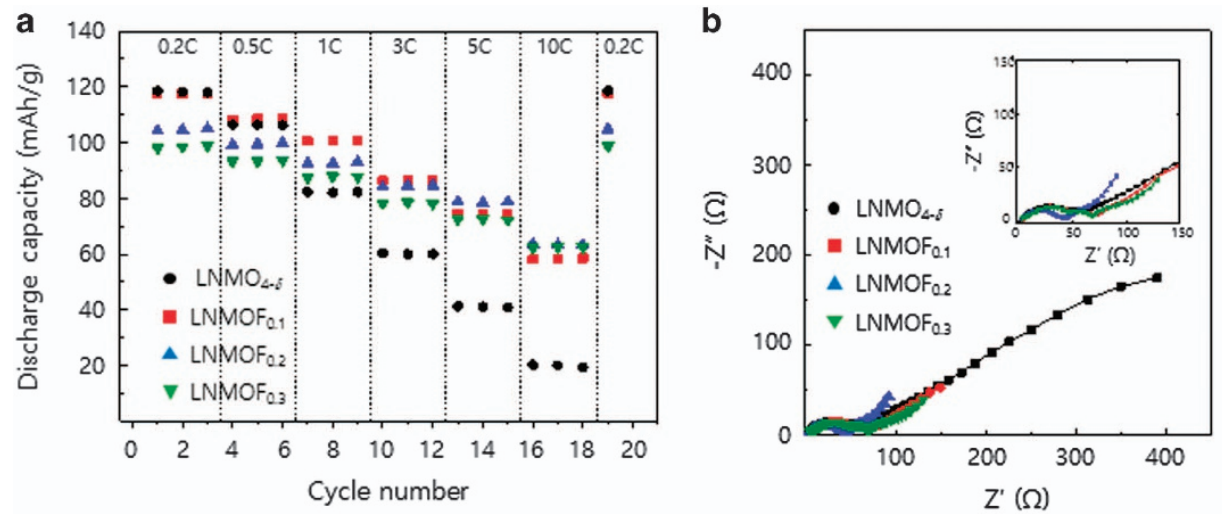

C

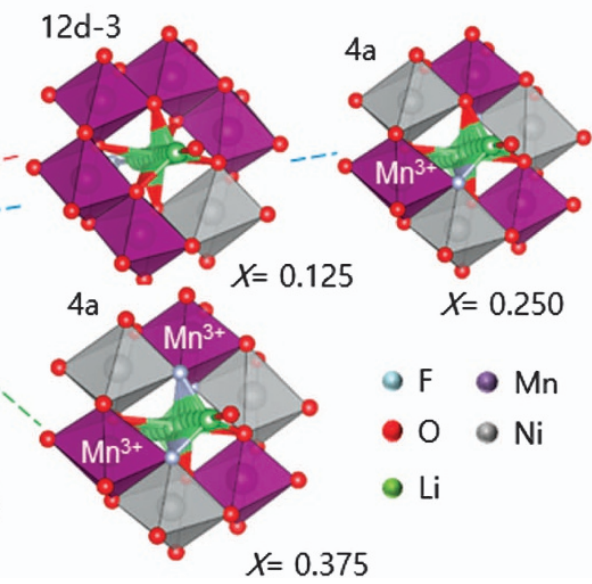

Figure 6 Lithium ion transportational characteristics in the $\mathrm{LiNi}_{0.5} \mathrm{Mn}_{1.5} \mathrm{O}_{4-x} \mathrm{~F}_{x}$ (LNMOF) electrodes. (a) C-rate capabilities and (b) Nyquist plot. The kinetic parameters were determined by electrochemical impedance spectroscopy (EIS) approaches. The Nyquist plots were fitted using the equivalent circuit model. The high- and low-frequency semicircles are attributed to surface film resistance $\left(R_{\mathrm{sf}}\right)$ and charge transfer resistance $\left(R_{\mathrm{ct}}\right)$ at the electrode-electrolyte interface, respectively. The Li-ion diffusion coefficient from the relation between the real impedance and the angular frequency in the low-frequency region were further estimated to evaluate quantitatively the $\mathrm{F}^{-}$-substitution effects. (c) Lithium ion hoping energy as a function of $\mathrm{F}$ content. The calculated energy profiles for lithium-ion hopping along the $8 c-4 a / 12 d-8 c$ route with the smallest activation barrier for ion hopping in LNMO and series of LNMOF crystals (12d-3 model in $x=0.125$, 4a model in $x=0.25$ and 4 a model in $x=0.375$ in Supplementary Figure 6 ).

hence, their contribution to the oxidation reaction during delithiation is very small. Figure 5 shows the change in the PDOS for the Mn-3d bands at different $\mathrm{Li}$ compositions. The manganese ions formed the Mn@2F arrangement (red line in Figures $5 \mathrm{c}$ and d) and did not change their original PDOS profile, even in the delithiated phase, which indicates that they remain in the $\mathrm{Mn}^{3+}$ oxidation state. Thus, $\mathrm{Mn}^{3+}$ coordinated with two fluorine anions in $\mathrm{Mn@2F} \mathrm{provided} \mathrm{a}$ small contribution to the redox reaction in $\mathrm{Li}_{0.125} \mathrm{Ni}_{0.5} \mathrm{Mn}_{1.5} \mathrm{O}_{4-}{ }_{x} \mathrm{~F}_{x}$ $(0.25<x \leq 0.375)$ through an electrochemical delithiation reaction within the cutoff voltage range of $3.5-4.9 \mathrm{~V}$.

$\mathrm{Mn}^{3+}$ bonded with the fluorine anions and required higher potential energies for oxidation: $3.86 \mathrm{~V}$ for $\mathrm{Mn} @ 1 \mathrm{~F}, 4.44 \mathrm{~V}$ for the Mn@2F neighbor and >5.04 V for Mn@2F diagonal in $x=0.375$, compared with that of $\mathrm{F}^{-}$-free $\mathrm{Mn}^{3+}$. The incorporated $\mathrm{F}^{-}$stabilized $\mathrm{Mn}^{3+}$ and inhibited its oxidation reaction via the electrochemical delithiation reaction. Two $\mathrm{F}^{-}$ions were orthogonally coordinated with $\mathrm{Mn}^{3+}$ along the $d_{z^{2}}$ and $d_{x^{2}-y^{2}}$ directions in the Mn@2F neighbor; therefore, one $\mathrm{F}^{-}$ion in the $\mathrm{Mn} @ 2 \mathrm{~F}$ orthogonal arrangement stabilized the $d_{z^{2}}$ orbital and the other $\mathrm{F}^{-}$ion stabilized the $d_{x^{2}-y^{2}}$ orbital. In contrast, two $\mathrm{F}^{-}$ions cooperatively and powerfully stabilized the $d_{z^{2}}$ orbital of diagonal Mn@2F. These are the most important results for a full understanding of mixed- $\mathrm{F}^{-}$effects on the intercalationdeintercalation characteristics of Li manganese oxides with spinel frameworks.
The computationally predicted delithiation characteristics with respect to the coordination numbers of $\mathrm{Mn}-\mathrm{F}$ bonding were further established using ex situ XAFS on the Mn $K$ edge. Changes in the valence states of $\mathrm{Mn}^{4+}$ in $\mathrm{LNMO}, \mathrm{LNMOF}_{0.1}$ and $\mathrm{LNMOF}_{0.3}$ with different SOCs ( 0 and 75\%) were estimated based on the energy shift at 0.9 for the main absorption height. The peak positions and their shifts are summarized in Supplementary Figure S5. A sufficient tendency to explain the effects of fluorine substitution on the capacity fade was observed even though the peak positions with different amounts of $\mathrm{F}^{-}$substitution and the peak shift at different SOCs were very small. The positions of the absorption peaks at SOC $=0 \%$ shifted to the lower energy side with increasing $\mathrm{F}^{-}$. The formation of the $\mathrm{Mn}-\mathrm{F}$ coordination bond reduced $\mathrm{Mn}^{4+}$ to $\mathrm{Mn}^{3+}$. Furthermore, all peaks shifted to a higher energy site after charging; thus, $\mathrm{Mn}^{3+}$ was oxidized to $\mathrm{Mn}^{4+}$. Increasing the $\mathrm{F}^{-}$substitution decreased the amount of shift. These features strongly support our computational predictions and considerations for the capacity fade of LNMOF.

The C-rate capability was performed to examine the mixed-fluorine-anion effect on the kinetics of $\mathrm{Li}$ ion transport. The $\mathrm{LNMO}_{4-\delta}$ cathode showed the highest discharge capacity at a low current density. However, it showed a greater capacity fade with an increasing current density than that for LNMOF (Figure 6a). While the series of LNMOF cathodes showed a lower discharge capacity at a low C-rate, their capacity dropped because the increased internal 
a

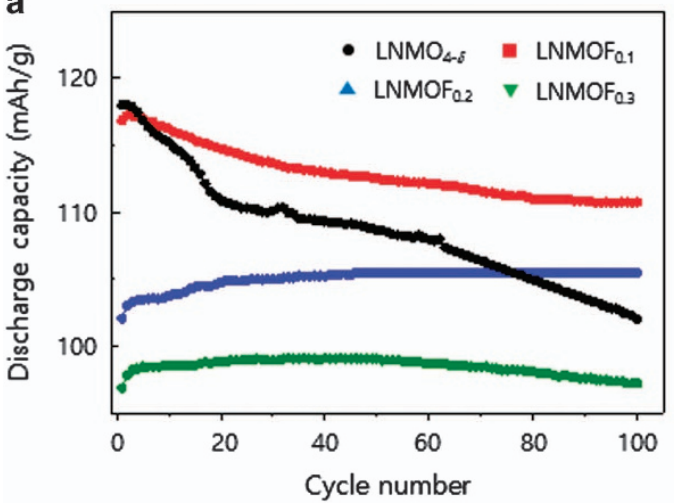

b

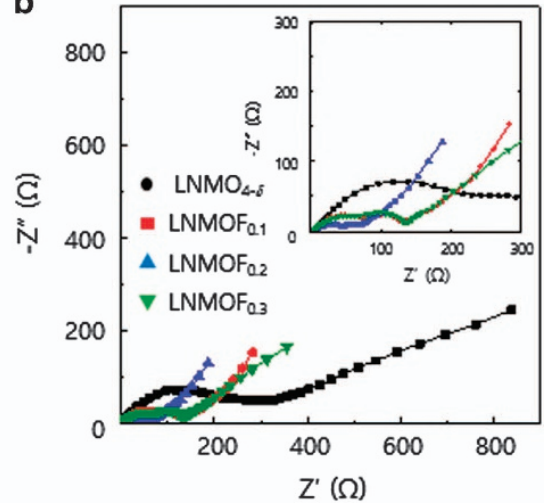

Figure 7 Cycle performances of the $\mathrm{LiNi}_{0.5} \mathrm{Mn}_{1.5} \mathrm{O}_{4-x} \mathrm{~F}_{x}$ (LNMOF) electrodes. (a) Cyclabilities at a $0.2 \mathrm{C}$-rate, and the discharge capacity vs cycle number for $\mathrm{LNMO}_{4-\delta}$ and a series of LNMOF cathodes/Li cells cycled at $23^{\circ} \mathrm{C}$ with a current corresponding to $0.2^{\circ} \mathrm{C}$. (b) Impedance spectra taken after the 100 th cycling test at a $0.2 \mathrm{C}$-rate and $23^{\circ} \mathrm{C}$.

resistance with increasing current density markedly improved. The incorporation of $\mathrm{F}^{-}$affects the electrochemical $\mathrm{Li}$ intercalation kinetics, which are strongly associated with the bulk properties of the electrode materials (e.g., electron conductivity and $\mathrm{Li}$ ion conductivity), and the kinetic parameters at the electrode-electrolyte interface.

The kinetic parameters were determined by EIS approaches. Figure $6 \mathrm{~b}$ shows the Nyquist plots of the $\mathrm{LNMO}_{4-\delta}$ and LNMOF electrodes. The impedance spectra were fitted using the equivalent circuit model. The high- and low-frequency semicircles are attributed to surface film resistance $\left(R_{\mathrm{sf}}\right)$ and charge transfer resistance $\left(R_{\mathrm{ct}}\right)$, respectively, at the electrode-electrolyte interface. We further calculated the Li-ion diffusion coefficient from the relation between the real impedance and the angular frequency in the low-frequency region to evaluate quantitatively the $\mathrm{F}^{-}$-substitution effects. The kinetic parameters are summarized in Supplementary Table S4. Increasing the mixed- $\mathrm{F}^{-}$content effectively reduced $R_{\mathrm{sf}}$ and $R_{\mathrm{ct}}$, and they reached minimum values for $\mathrm{LNMOF}_{0.3}$. Further $\mathrm{F}^{-}$substitution increased the resistance, which might correspond to disturbed $\mathrm{Li}$ ion migration by excess amounts of $\mathrm{F}^{-}$.

The relationship between $\mathrm{Li}$ ion migration and fluorine anion substitution was considered using DFT calculations to predict Li-ion migration paths (Figure 6c). The $\mathrm{Li}$ ion in the spinel framework preferentially migrated along the $8 c-4 a / 12 d-8 c$ route, independent of $\mathrm{F}^{-}$substitution. In the considerable migration models shown in Supplementary Figure S6, the activation barrier for ion hopping in the LNMO and series of LNMOF crystals was the smallest in the 12d-3 model at $x=0.125(0.37 \mathrm{eV}), 4 \mathrm{a}$ model at $x=0.25(0.33 \mathrm{eV})$ and $4 \mathrm{a}$ model at $x=0.375(0.44 \mathrm{eV})$. In particular, the $\mathrm{LNMOF}_{0.2}$ cathode showed minimum activation energies and the highest $\mathrm{Li}$ ion conductivity, which agree with the C-rate capability test.

The migration paths and their corresponding activation energy profiles for $\mathrm{Li}^{+}$hopping along $8 \mathrm{c}-4 \mathrm{a} / 12 \mathrm{~d}-8 \mathrm{c}$ in stoichiometric LNMO, non-stoichiometric $\mathrm{LNMO}_{4-\delta}$ and $\mathrm{LNMOF}_{0.1}$ are summarized in Supplementary Figure S7. These results indicate that the migration path and the activation energy for $\mathrm{Li}^{+}$hopping strongly depend on the interaction between $\mathrm{V}_{\mathrm{Li}}^{\prime}$ at the $8 \mathrm{c}-4 \mathrm{a} / 12 \mathrm{~d}-8 \mathrm{c}$ site and $\mathrm{O}_{\mathrm{O}}^{\times}, \mathrm{V}_{\mathrm{O}}^{*}$ or $\mathrm{F}_{\mathrm{O}}^{\cdot}$ at the $24 e$ site. The $\mathrm{Li}^{+}$ion in stoichiometric LNMO moves in a straight line along the migration path, as shown for spinel $\mathrm{Li}_{4} \mathrm{Ti}_{5} \mathrm{O}_{12}{ }^{46}$ In contrast, $\mathrm{Li}^{+}$in $\mathrm{LNMO}_{4-\delta}$ and $\mathrm{LNMOF}_{0.1}$ migrates tortuously at $\mathrm{V}_{\mathrm{O}}^{*}$ and $\mathrm{F}_{\mathrm{O}}^{*}$, respectively. Replacing $\mathrm{V}_{\mathrm{O}}^{*}$ with $\mathrm{F}_{\mathrm{O}}$ mitigated the tortuous $\mathrm{Li}^{+}$migration path and lowered the activation energy from $1 \mathrm{eV}$ to $\sim 0.5 \mathrm{eV}$, as required for $\mathrm{Li}^{+}$hopping because the coordination number of the $\mathrm{Li}^{+}$ion at $8 \mathrm{c}-4 \mathrm{a} / 12 \mathrm{~d}-8 \mathrm{c}$ in $\mathrm{LNMOF}_{0.1}$ remained three (two oxygen and one fluorine), even though that of LNMO was two (two oxygen).

Li-ion hopping can be interpreted as Li ion vacancy $\left(\mathrm{V}_{\mathrm{Li}}^{\prime}\right)$ hopping. Generally, the valence state for $\mathrm{V}_{\mathrm{Li}}^{\prime}$ is negatively charged. Therefore, $\mathrm{F}_{\mathrm{O}}^{*}$ slightly changed the charged state of the $4 a / 12 d$ site $\left(\mathrm{V}_{\mathrm{Li}}^{\prime}\right)$ and became more positive because of the different valence states. The activation barrier for $\mathrm{Li}$-ion hopping along the $8 c-4 a / 12 d-8 c$ path became larger because the $\mathrm{Li}$ ion path was more positively charged. In other words, $\mathrm{V}_{\mathrm{Li}}^{\prime}$ is strongly trapped with $\mathrm{F}_{\mathrm{O}}^{\cdot}$ because of defect aggregation. In contrast, the DFT calculations revealed that incorporating $\mathrm{F}^{-}$strongly affected $\mathrm{Li}$ ion conductivity in non-stoichiometric $\mathrm{LNMO}_{4-\delta}$ with $\mathrm{V}_{\mathrm{O}}^{*}$. The charged state of the $4 a / 12 d$ site in non-stoichiometric LNMO became much more positive after the formation of a $V_{\mathrm{O}}$ at the $24 e$ site compared with that of stoichiometric LNMO. Replacing $\mathrm{V}_{\mathrm{O}}^{\cdot}$ at the $24 e$ site with $\mathrm{F}_{\mathrm{O}}^{\cdot}$ reduced the activation energy for Li-ion hopping because of the relaxed electrostatic repulsion at the $4 a / 12 d$ site of $\mathrm{LNMO}_{4-\delta}$, which was positively charged.

Fluorine anion substitution-dependent changes to the Li-ion hopping route were not seen; however, their activation barrier changed significantly with respect to the symmetry in the site potential of the two tetrahedral $8 c$ sites adjacent to the octahedral $4 a / 12 d$ sites in the Li-ion diffusion path. A symmetric site potential across $8 c-4 a-8 c$ was formed in $\mathrm{LNMOF}_{0.2}$ by the substitution of a single $\mathrm{F}^{-}$ in both tetrahedral $8 c$ sites, leading to a site potential minimum (which is in contrast to those of asymmetric $\mathrm{LNMOF}_{0.1}$ and $\mathrm{LNMOF}_{0.3}$, whose activation barriers were higher than that of $\left.\mathrm{LNMOF}_{0.2}\right)$. Oxygen vacancies in the two tetrahedral $8 c$ sites adjusted to the octahedral $4 a / 12 d$ site and were inhomogeneously substituted with $\mathrm{F}^{-}$to form different $\mathrm{Li}-\mathrm{F}$ coordination numbers in $\mathrm{LNMOF}_{0.1}$ $\left(\mathrm{Li}_{8 c}{ }^{x} @ 1 \mathrm{~F}_{24 e^{-}}-\mathrm{Li}_{8 c}{ }^{x} @ \mathrm{O}_{24 e^{x}}\right)$ and $\mathrm{LNMOF}_{0.3}\left(\mathrm{Li}_{8 c}{ }^{x} @ 1 \mathrm{~F}_{24 e^{-}}-\mathrm{Li}_{8 c}{ }^{x} @ 2 \mathrm{~F}_{24 e}\right)$, which imbalanced the site potential and increased the activation barrier for ion hopping. These calculations agreed with the experimentally demonstrated C-rate capability and EIS results.

Figure $7 \mathrm{a}$ shows the discharge capacity vs cycle number for $\mathrm{LNMO}_{4-\delta}$ and a series of LNMOF cathodes/Li cells cycled at $23^{\circ} \mathrm{C}$ with a current corresponding to $0.2^{\circ} \mathrm{C}$. A significant capacity loss with cycle number was observed to $80 \%$ of the initial capacity for the $\mathrm{LNMO}_{4-\delta} / \mathrm{Li}$ cells after 100 cycles; all of the fluorine-substituted LNMOF/Li cells showed an obvious improvement in the cyclability with capacity retentions $>90 \%$. The $\mathrm{LNMOF}_{0.2} / \mathrm{Li}$ cell showed almost no capacity loss during cycling. The coulomb efficiency of the cell was 
almost constant at $\sim 0.990$ during the cycles. Furthermore, EIS experiments for the cells after 100 cycles (Figure 7b) showed that the all-kinetic parameters $\left(R_{\mathrm{sf}}, R_{\mathrm{ct}}\right.$ and $\left.D_{\mathrm{Li}}\right)$ degraded with cycling; however, the deterioration of the $\mathrm{LNMOF}_{0.2} / \mathrm{Li}$ cell was significantly smaller (Supplementary Table S5). Fluorine anion substitution likely suppressed the dissolution of the manganese ion into the electrolyte and metal-fluoride formation as a solid electrolyte interface by oxidative decomposition of the liquid electrolyte at high voltages. The computational studies implied that the stabilization of $\mathrm{Mn}^{3+}$ by neighboring $\mathrm{F}^{-}$(formation of coordination bonds and enhancement of Jahn-Teller distortion) primarily contributed to the significant cyclability improvement. Furthermore, we reported that surface modifications of the LNMO crystals with $<2$-nm-thick fluoroalkylsilane monolayers improved the cyclability by enhancing the lyophobic characteristics against liquid electrolytes. ${ }^{35}$ The mixed $\mathrm{F}^{-}$lowered the surface energy by inducing segregation near the surface. A similar surface modification was imparted by the fluoroalkylsilane monolayer and will contribute in improving the cycle characteristics. Based on the changes in the $\mathrm{Mn}^{3+} / \mathrm{Mn}^{4+}$ ratio of the XPS-Mn core-level spectra taken from the electrode surface after cycling, we showed that $\mathrm{Mn}^{3+}$ does not go through the notorious disproportionation reaction. The absence ratio of $\mathrm{Mn}^{3+}$ was sufficiently retained in the LNMO stabilized with the fluoroalkylsilane monolayer compared with that of bare LNMO. Furthermore, retention of dark pigments was observed on the polypropylene separator after 100 cycles in the LNMO/Li cell, unlike that in the $\mathrm{LNMOF}_{0.2} / \mathrm{Li}$ cells. The batteries were reusable after replacing an old separator with a new one. These results strongly suggest that the incorporation of $\mathrm{F}^{-}$into the LNMO lattice prevents the risk for higher capacity fading under high-voltage operation because of the occurrence of a short circuit caused by $\mathrm{Mn}^{3+}$ dissolution during cycling.

In summary, we determined the effect of mixed-fluorine anions in oxygen-deficient, spinel-type $\mathrm{LNMO}_{4-\delta}$ crystals on the structural, electrical and electrochemical characteristics by experimental and computational approaches. This is the first report that provides the full picture for mixed-fluorine-anion effects on high-voltage spinel manganese cathodes. The anion-mixed effects are an exciting new direction for the development of high-voltage cathode materials.

\section{CONFLICT OF INTEREST}

The authors declare no conflict of interest.

\section{ACKNOWLEDGEMENTS}

This work was partially supported by JST-CREST (JPMJCR1322), Japan. GSS, RI and YI acknowledge the Research Hub for Advanced Nano Characterization, the University of Tokyo, under the support of 'Nanotechnology Platform' (project no. 12024046) by MEXT, Japan.

1 Armand, M. \& Tarascon, J. M. Building better batteries. Nature 451, 652-657 (2008).

2 Winter, M. \& Brodd, R. J. What are batteries, fuel cells, and supercapacitors? Chem Rev. 104, 4245-4270 (2004).

3 Padhi, A. K., Nanjundaswamy, K. S. \& Goodenough, J. B. Phospho-olivines as positiveelectrode materials for rechargeable lithium batteries. J. Electrochem. Soc. 148, 1188-1194 (1997).

4 Liu, G. Q., Wen, L. \& Liu, Y. M. LiNi $0.5 \mathrm{Mn}_{1.5} \mathrm{O}_{4}$ and its derivatives as cathodes for highvoltage Li-ion batteries. J Solid State Electrochem 14, 2191-2202 (2010).

5 Santhanam, R. \& Rambabu, B. Research progress in high voltage spinel $\mathrm{LiNi}_{0.5} \mathrm{Mnn}_{1.5} \mathrm{O}_{4}$ material. J. Power Sources 195, 5442-5451 (2010).

6 Goodenough, J. B. \& Kim, Y. Challenges for rechargeable Li batteries. Chem. Mater. 22, 587-603 (2010).
7 Shiiba, H., Zettsu, N., Nakayama, M., Oishi, S. \& Teshima, K. Defect formation energy in spinel $\mathrm{LiNi}_{0.5} \mathrm{Mn}_{1.5} \mathrm{O}_{4-\delta}$ using ab initio DFT calculations. J. Phys. Chem. C 119, 9117-9124 (2015).

8 Terada, Y., Yasaka, K., Nishikawa, F., Konishi, T., Yoshio, M. \& Nakai, I. In situ XAFS analysis of $\mathrm{Li}\left(\mathrm{Mn}, \mathrm{M}_{2} \mathrm{O}_{4}(\mathrm{M}=\mathrm{Cr}\right.$, $\mathrm{Co}, \mathrm{Ni}) 5 \mathrm{~V}$ cathode materials for lithium-ion secondary batteries. J. Solid State Chem. 156, 286-291 (2001).

9 Dokko, K., Mohamedi, M., Anzue, N., Itoh, T. \& Uchida, I. In situ Raman spectroscopic studies of $\mathrm{LiNi}_{x} \mathrm{Mn}_{2-x} \mathrm{O}_{4}$ thin film cathode materials for lithium ion secondary batteries. J. Mater. Chem. 12, 3688-3693 (2002).

10 Yang, T., Zhang, N., Lang, Y. \& Sun, K. Enhanced rate performance of carbon-coated $\mathrm{LiNi}_{0.5} \mathrm{Mn}_{1.5} \mathrm{O}_{4}$ cathode material for lithium ion batteries. Electrochim. Acta 56, 4058-4064 (2011).

11 Wang, L., Li, H., Huang, X. \& Baudrin, E. A comparative study of Fd-3m and $\mathrm{P}_{3} 32$ " $\mathrm{LiNi}_{0.5} \mathrm{Mn}_{1.5} \mathrm{O}_{4}$ ". Solid State lonics 193, 32-38 (2011).

12 Kunduraci, M., Al-Sharab, J. F. \& Amatucci, G. G. High-power nanostructured $\mathrm{LiMn}_{2-x} \mathrm{Ni}_{x} \mathrm{O}_{4}$ high-voltage lithium-ion battery electrode materials: electrochemical impact of electronic conductivity and morphology. Chem. Mater. 18, 3585-3592 (2006).

13 Verhoeven, V. W. J., Mulder, F. M. \& de Schepper, I. M. Influence of Mn by Li substitution on the Jahn-Teller distortion in $\mathrm{LiMn}_{2} \mathrm{O}_{4}$. PhysB 276, 950-951 (2000).

14 Singh, G., Gupta, S. L., Prasad, R., Auluck, S., Gupta, R. \& Sil, A. Suppression of JahnTeller distortion by chromium and magnesium doping in spinel $\mathrm{LiMn}_{2} \mathrm{O}_{4}$ a firstprinciples study using GGA and GGA+U. J Phys. Chem. Solids 70, 1200-1206 (2009).

15 Ouyang, C. Y., Shi, S. Q. \& Lei, M. S. Jahn-Teller distortion and electronic structure of $\mathrm{LiMn}_{2} \mathrm{O}_{4}$. J. Alloys Compd. 474, 370-374 (2009).

16 Park, S. H. \& Sun, Y. K. Synthesis and electrochemical properties of $5 \mathrm{~V}$ spinel $\mathrm{LiNi}_{0.5} \mathrm{Mn}_{1.5} \mathrm{O}_{4}$ cathode materials prepared by ultrasonic spray pyrolysis method. Electrochim. Acta 50, 434-439 (2004).

17 Yi, T. F., Xie, Y., Ye, M. F., Jiang, L. J., Zhu, R. S. \& Zhu, Y. R. Recent developments in the vDoping of $\mathrm{LiNi}_{0.5} \mathrm{Mn}_{1.5} \mathrm{O}_{4}$ cathode material for $5 \mathrm{~V}$ lithium-ion batteries. Ionics 17 , 383-389 (2001).

18 Zhong, G. B., Wang, Y. Y., Zhang, Z. C. \& Chen, C. H. Effects of Al substitution for Ni and $\mathrm{Mn}$ on the electrochemical properties of $\mathrm{LiNi}_{0.5} \mathrm{Mn}_{1.5} \mathrm{O}_{4}$. Electrochim. Acta 56, 6554-6561 (2011).

19 Aklalouch, M., Amarilla, J. M., Rojas, R. M., Saadoune, I. \& Rojo, J. M. Chromium doping as a new approach to improve the cycling performance at high temperature of $5 \mathrm{~V} \mathrm{LiNi}_{0.5} \mathrm{Mn}_{1.5} \mathrm{O}_{4}$-based positive electrode. J. Power Sources 185, 501-511 (2008).

20 Ito, A., Li, D., Lee, Y., Kobayakawa, K. \& Sato, Y. Influence of Co substitution for Ni and $\mathrm{Mn}$ on the structural and electrochemical characteristics of $\mathrm{LiNi}_{0.5} \mathrm{Mn}_{1.5} \mathrm{O}_{4}$. J. Power Sources 185, 1429-1433 (2008).

21 Oh, S. H., Chung, K. Y., Jeon, S. H., Kim, C. S., Cho, W. I. \& Cho, B. W. Structural and electrochemical investigations on the $\mathrm{LiNi}_{0.5-x} \mathrm{Mn}_{1.5-y} \mathrm{M}_{x+y} \mathrm{O}_{4}(\mathrm{M}=\mathrm{Cr}, \mathrm{Al}, \mathrm{Zr})$ compound for 5V cathode material. J. Alloys Compd. 469, 244-250 (2009).

22 Park, S. B., Eom, W. S., Cho, W. I. \& Jang, H. Electrochemical properties of $\mathrm{LiNi}_{0.5} \mathrm{Mn}_{1.5} \mathrm{O}_{4}$ cathode after $\mathrm{Cr}$ doping. J. Power Sources 159, 679-684 (2006).

23 Wang, H., Xia, H., Lai, M. O. \& Lu, L. Enhancements of rate capability and cyclic performance of spinel $\mathrm{LiNi}_{0.5} \mathrm{Mn}_{1.5} \mathrm{O}_{4}$ by trace Ru-doping. Electrochem. Commun. 11, 1539-1542 (2009).

24 Alcantara, R., Jaraba, M., Lavela, P., Tirado, J. L., Zhecheva, E. \& Stoyanova, R. Changes in the local structure of $\mathrm{LiMg}_{\mathrm{N}} \mathrm{Ni}_{0.5} \mathrm{Mnn}_{1.5} \mathrm{O}_{4}$ electrode materials during lithium extraction. Chem. Mater. 16, 1573-1579 (2004).

$25 \mathrm{Liu}$, J. \& Manthiram, A. Understanding the improved electrochemical performances of Fe-substituted $5 \mathrm{~V}$ spinel cathode $\mathrm{LiNi}_{0.5} \mathrm{Mnn}_{1.5} \mathrm{O}_{4}$. J. Phys. Chem. C 113, 15073-15079 (2009).

26 Schroeder, M., Glatthaar, S., Geßwein, H., Winkler, V., Bruns, M., Scherer, T., Chakravadhanula, V. S. K. \& Binder, J. R. Post-doping via spray-drying: a novel solgel process for the batch synthesis of doped $\mathrm{LiNi}_{0.5} \mathrm{Mnn}_{1.5} \mathrm{O}_{4}$ spinel material. J. Mater Sci. 48, 3404-3414 (2013).

27 Wen, W., Ju, B., Wang, X.,Wu, C., Shu, H. \& Yang, X. Effects of magnesium and fluorine Co-doping on the structural and electrochemical performance of the spinel $\mathrm{LiMn}_{2} \mathrm{O}_{4}$ cathode materials. Electrochim. Acta 147, 271-278 (2014).

28 Hagh, N. M. \& Amatucci, G. G. Effect of cation and anion doping on microstructure and electrochemical properties of the $\mathrm{LiNi}_{0.5} \mathrm{Mn}_{1.5} \mathrm{O}_{4-\delta}$ spinel. J. Power Sources 256, 457-469 (2014).

29 Oh, S. W., Park, S. H., Kim, J. H., Bae, Y. C. \& Sun, Y. K. Improvement of electrochemical properties of $\mathrm{LiNi}_{0.5} \mathrm{Mn}_{1.5} \mathrm{O}_{4}$ spinel material by fluorine substitution. J. Power Sources 157, 464-470 (2006).

$30 \mathrm{Du}, \mathrm{G}$., NuLi, Y., Yang, J. \& Wang, J. Fluorine-doped $\mathrm{LiNi}_{0.5} \mathrm{Mn}_{1.5} \mathrm{O}_{4}$ for $5 \mathrm{v}$ cathode materials of lithium-ion battery. Mater. Res. Bull. 43, 3607-3613 (2008).

31 Lee, E. \& Persson, K. A. Revealing the coupled cation interactions behind the electrochemical profile of $\mathrm{Li}_{x} \mathrm{Ni}_{0.5} \mathrm{Mn}{ }_{1.5} \mathrm{O}_{4}$. Energy Environ. Sci. 5, 6047-6051 (2012).

32 Schmidt, R., Basu, A. \& Brinkman, A. W. Small polaron hopping in spinel manganates. Phys. Rev. B 72, 115101-115110 (2005).

33 Schmidt, R., Basu, A., Brinkman, A. W., Klusek, Z. \& Datta, P. K. Electron-hopping modes in $\mathrm{NiMn}_{2} \mathrm{O}_{4+\delta}$ materials. Appl. Phys. Lett. 86, $073501-073504$ (2005).

34 Xiao, J., Chen, X., Sushko, P. V., Sushko, M. L., Kovarik, L., Feng, J., Deng, Z., Zheng, J., Graff, G. L., Nie, Z., Choi, D., Liu, J., Zhang, J. G. \& Whittingham, M. S. Highperformance $\mathrm{LiNi}_{0.5} \mathrm{Mn}_{1.5} \mathrm{O}_{4}$ spinel controlled by $\mathrm{Mn}^{3+}$ concentration and site disorder. Adv. Mater. 24, 2109-2116 (2012).

35 Zettsu, N., Kida, S., Uchida, S. \& Teshima, K. Sub-2 nm thick fluoroalkylsilane self-assembled monolayer-coated high voltage spinel crystals as promising cathode materials for lithium ion batteries. Sci. Rep. 6, 31999 (2016). 
36 Kresse, G \& Furthmuller, J. Efficient iterative schemes for ab initio total-energy calculations using a plane-wave basis set. Phys. Rev. B 54, 11169-11186 (1996).

37 Kresse, G \& Furthmuller, J. Efficiency of ab-initio total energy calculations for metals and semiconductors using a plane-wave basis set. Comput. Mater. Sci. 6, 15-50 (1996).

38 Perdew, J. P. Ruzsinszky, A., Csonka, G. I., Vydrov, O. A., Scuseria, G. E., Constantin, L. A., Zhou, X. \& Burke, K. Restoring the density-gradient expansion for exchange in solids and surfaces. Phys. Rev. Lett. 100, 136406-136409 (2008).

39 Blöchl, P. E. Projector augmented-wave method. Phys. Rev. B 50, 17953-17979 (1994).

40 Jain, A, Hautier, G., Ong, S. P., Moore, C. J., Fischer, C. C., Persson, K. A. \& Ceder, G. Formation enthalpies by mixing GGA and GGA+U calculations. Phys. Rev. B 84 045115 (2011)

41 Muller, T, Hautier, G, Jain, A \& Ceder, G. Evaluation of tavorite-structured cathode materials for lithium-ion batteries using high-throughput computing. Mater. Chem. 23, 3854-3862 (2011).

42 Hautier, G, Ong, S. P, Jain, A, Moore, C. J \& Ceder, G. Accuracy of density functional theory in predicting formation energies of ternary oxides from binary oxides and its implication on phase stability. Phys. Rev. B 85, 155208 (2012).

43 Biškup, N., Martínez, J.L., Arroyo y de Dompablo, M. E., Díaz-Carrasco, P. \& Morales, J. Relation between the magnetic properties and the crystal and electronic structures of manganese spinels $\mathrm{LiNi}_{0.5} \mathrm{Mn}_{1.5} \mathrm{O}_{4}$ and $\mathrm{LiCu}_{0.5} \mathrm{Mn}_{1.5} \mathrm{O}_{4-\delta}(0<\delta<0.125)$. J. Appl. Phys. 100, 093908 (2006).

44 Amdouni, N., Zaghib, K., Gendron, F., Mauger, A. \& Julien, C. M. Magnetic properties of $\mathrm{LiNi}_{0.5} \mathrm{Mnn}_{1.5} \mathrm{O}_{4}$ spinels prepared by wet chemical methods. J. Magn. Magn. Mater. 309, 100-105 (2007).

45 Chen, Y., Sun, Y. \& Huang, X. Origin of the Ni/Mn ordering in high-voltage spinel $\mathrm{LiNi}_{0.5} \mathrm{Mn}_{1.5} \mathrm{O}_{4}$ : the role of oxygen vacancies and cation doping. Comp. Mater. Sci. 115, 109-116 (2016).

46 Shiiba, H., Nakayama, M. \& Nogami, M. Ionic conductivity of lithium in spinel-type $\mathrm{Li}_{4 / 3} \mathrm{Ti}_{5 / 3} \mathrm{O}_{4}-\mathrm{LiMg}_{1 / 2} \mathrm{Ti}_{3 / 2} \mathrm{O}_{4}$ solid-solution system. Solid State lonics 181, 994-1001 (2010).
47 Jonsson, H., Mills, G., Jacobsen, K. W., Berne, B. J. in Classical and Quantum Dynamics in Condensed Phase Simulations (eds Chandler D., Berne B. J., Ciccotti G. \& Coker D. F.) 385-404 (World Scientific: Singapore, 1998).

48 Sushko, P. V., Rosso, K. M., Zhang, J. G., Liu, J. \& Sushko, M. L. Oxygen vacancies and ordering of D-levels control voltage suppression in oxide cathodes: the case of spinel $\mathrm{LiNi}_{0.5} \mathrm{Mn}_{1.5} \mathrm{O}_{4-\delta}$. Adv. Funct. Mater. 23, 5530-5535 (2013).

49 Jafta, C. J., Mathe, M. K., Manyala, N., Roos, W. D. \& Ozoemena, K. I. Microwaveassisted synthesis of high-voltage nanostructured $\mathrm{LiNi}_{0.5} \mathrm{Mnn}_{1.5} \mathrm{O}_{4}$ spinel: tuning the $\mathrm{Mn}^{3+}$ content and electrochemical performance. Appl. Mater. Interfaces 5, 7592-7598 (2013).

50 Xia, H., Meng, Y. S., Lu, L. \& Ceder, G. Electrochemical properties of nonstoichiometric $\mathrm{LiNi}_{0.5} \mathrm{Mn}_{1.5} \mathrm{O}_{4-\delta}$ thin-film electrodes prepared by pulsed laser deposition. J. Electrochem. Soc. 154, A737-A743 (2007).

51 Kim, J. H., Myung, S. T., Yoon, C. S., Kang, S. G. \& Sun, Y. K. Comparative study of LiNi ${ }_{0.5} \mathrm{Mn}_{1.5} \mathrm{O}_{4-\delta}$ and $\mathrm{LiNi}_{0.5} \mathrm{Mn}_{1.5} \mathrm{O}_{4}$ cathodes having two crystallographic structures: Fd-3M and $\mathrm{P}_{3} 32$. Chem. Mater. 16, 906-914 (2004).

\section{cc) (i)}

This work is licensed under a Creative Commons Attribution 4.0 International License. The images or other third party material in this article are included in the article's Creative Commons license, unless indicated otherwise in the credit line; if the material is not included under the Creative Commons license, users will need to obtain permission from the license holder to reproduce the material. To view a copy of this license, visit http:// creativecommons.org/licenses/by/4.0/

(C) The Author(s) 2017

Supplementary Information accompanies the paper on the NPG Asia Materials website (http://www.nature.com/am) 